\title{
Fluorinated surfactants in solution: Diffusion coefficients of fluorinated alcohols in water
}

\author{
Luís F.G. Martins ${ }^{\mathrm{a}, *}$, Luís A.M. Pereira ${ }^{\mathrm{a}}$, Gonçalo M.C. Silva ${ }^{\mathrm{b}}$, José R. Ascenso ${ }^{\mathrm{b}}$, \\ Pedro Morgado $^{\mathrm{b}}$, João P. Prates Ramalho ${ }^{\mathrm{a}}$, Eduardo J.M. Filipe ${ }^{\mathrm{b}}$ \\ a Centro de Química de Évora, Universidade de Évora, Rua Romão Ramalho, 59, 7000-671 Évora, Portugal \\ ${ }^{\mathrm{b}}$ Centro de Química Estrutural, Instituto Superior Técnico, Universidade de Lisboa, Av. Rovisco Pais, 1049-001 Lisboa, Portugal
}

\section{A R T I C L E I N F O}

\section{Article history:}

Received 7 April 2015

Received in revised form 7 June 2015

Accepted 8 June 2015

Available online 16 June 2015

\section{Keywords:}

Fluorinated alcohols

Diffusion coefficients

PFG-NMR spin-echo

Molecular dynamics

\begin{abstract}
A B S T R A C T
Intra-diffusion coefficients of three fluorinated alcohols, 2,2,3,3,3-pentafluoropropan-1-ol (PFP), 2,2,3,3,4,4,4-heptafluorobutan-1-ol (HFB) and 2,2,3,3,4,4,5,5,5-nonafluoropentan-1-ol (NFP) in water have been measured by the PFG-NMR spin-echo technique as a function of temperature and composition, focusing on the alcohol dilute region. For comparison, intra-diffusion coefficients of 2,2,2trifluoroethanol (TFE) and HFB have also been measured in heavy water using the same method and conditions. As far as we know, these are the first experimental measurements of this property for these binary systems. Intra-diffusion coefficients for NFP in water and for TFE and HFB in heavy water have also been obtained by molecular dynamics simulation, complementing those for TFE, PFP and HFB reported in a previous work. The agreement between experimental and simulated results for PFP, HFB and NFP in water is reasonable, although presenting higher deviations than for the TFE/water system. From the dependence of the intra-diffusion coefficients on temperature, diffusion activation energies were estimated for all the solutes in water and heavy water.
\end{abstract}

(c) 2015 Elsevier B.V. All rights reserved.

\section{Introduction}

Fluorinated surfactants are fascinating substances that ally a marked surfactant behavior of the hydrophilic/hydrophobic type, to lyophobic behavior towards hydrogenated organic media. Both characteristics result from the presence of the fluorinated chain that simultaneously displays an enhanced hydrophobicity compared to that of hydrogenated chains and a poorly understood antipathy relatively to common hydrogenated solvents.

Due to their many applications, fluorinated surfactants have become important industrial substances. They are used as adjuvant components in fluoropolymer manufacture and processing, aqueous foams for fire extinction, formulations of herbicides, greases and lubricants, paints, polishes and adhesives [1,2].

However it is in biomedical R\&D that fluorinated surfactants of different types and natures, have found the most exciting applications, for instance, as emulsifiers for blood substitute formulations [3] and inverse emulsions for drug delivery in liquid ventilation context [4] or as components of the walls of microbubbles used for drug delivery and oxygen transport in blood [5].

\footnotetext{
* Corresponding author. Fax: +351 266744971.

E-mail address: lfgm@uevora.pt (L.F.G. Martins).
}

The stability of all these biphasic nanostructured systems depends critically on the thermodynamic properties of the active substances and the surfactants, namely their surface tension and mobility in the continuous phase given by the diffusion coefficient.

Perfluorinated $n$-alcohols can be considered the simplest fluorosurfactants in terms of chemical structure. Their relative simplicity and the regularity of their thermodynamic properties, makes them the ideal starting point to interpret and predict the thermodynamic properties of fluorinated surfactants in a systematic fashion and to study them in theoretical and modeling terms. On the other hand, the range of industrial and scientific applications of fluorinated alcohols has become wider in the last decades. TFE has long been used in the study of proteins and peptides, as it induces conformational changes, helix formation and folding and stabilizes secondary structures in peptide chains [6]. It is also used as solvent in polymer manufacture and, mixed with water, as working fluid in refrigeration cycles and heat pumps [7]. Fluorinated propanols are used as co-solvents in protein studies, while HFB has potential applications as intermediate for organic synthesis and as surfactant in emulsions for oxygen transport. Both fluorinated propanols and butanols have been tested as co-solvents in supercritical extraction processes [8].

The thermodynamic behavior of aqueous solutions of $n$-fluoroalcohols also presents interesting features, with large 
negative excess volumes [9],s-shaped but mostly positive excess enthalpies $[10,11]$. A discontinuity in the compressibility versus composition behavior in dilute solutions of TFE has been recently reported [12]. However, data concerning the dynamic properties of these systems are very scarce, in particular for diffusion coefficients. The work of Harris et al. [13], who measured intradiffusion coefficients of TFE in water as a function of composition, constitutes a notable exception.

Binary mixtures involving fluorinated and hydrogenated alcohols are also interesting systems from the fundamental point of view, whose behavior has been studied over the last years in our group, hoping to clarify the effect of the combined presence of hydrogen bonding between molecules with mutually phobic segments (hydrogenated and perfluorinated) and how this affects the properties of the liquid mixture and induces organization. In the case of TFE + ethanol mixtures, the evaluation of the importance of the asymmetry in the distribution of hydrogen bonds between the two compounds, as well as the weak fluorinatedhydrogenated interaction, in their thermodynamic properties have been addressed [14].

In a recent paper [15] we have reported intra-diffusion coefficients of TFE in dilute aqueous solutions, extending the composition and temperature ranges of the results available in the literature. Molecular dynamics (MD) simulation results for this system closely reproduced the experimental ones, encouraging us to estimate the diffusion coefficients of aqueous PFP, HFB and the environmentally relevant PFOA and PFOS, by computer simulation.

As an extension of that work, we present here new experimental results of the intra-diffusion coefficients of PFP, HFB and NFP in water as well as intra-diffusion coefficients of TFE and HFB in heavy water $\left(D_{2} O\right)$, as a function of composition and temperature, in the dilute region. The experimental results are compared with those previously obtained by simulation. New MD simulations were also performed for NFP in water and for the systems involving heavy water.

\section{Experimental}

\subsection{Materials}

2,2,2-trifluoroethanol (99\%), supplied by Apollo Scientific, was distilled over potassium sulfate. 2,2,3,3,3-pentafluoropropan-1-ol (Apollo Scientific, 98\%), 2,2,3,3,4,4,4-heptafluorobutan-1-ol (Aldrich, 98\%) and 2,2,3,3,4,4,5,5,5-nonafluoropentan-1-ol were used as received. All the alcohols were stored in tightly closed bottles and handled under dry nitrogen. Water was purified in a Millipore filtration and ion exchange system to a final resistivity of 18.2 $\mathrm{M} \Omega \mathrm{cm}$. Deuterium oxide (Aldrich, 99.9\%) was also used as received and handled under dry nitrogen.

\subsection{Experimental methods}

Intra-diffusion coefficients were determined by Pulse Field Gradient-Nuclear Magnetic Resonance (PFG-NMR) spin-echo in a NMR Bruker Advance III $500 \mathrm{MHz}$ spectrometer. Two different probes have been used: $5 \mathrm{~mm}$ TXI (Triple Resonance) probe for ${ }^{1} \mathrm{H}$ and a $5 \mathrm{~mm}$ BBO (Double Resonance Broad Band) probe tuned to observe both ${ }^{19} \mathrm{~F}$ and ${ }^{1} \mathrm{H}$. A bipolar stimulated echo sequence (BPPLED-Bipolar Pulse Longitudinal Eddy Current Delay) with sine shaped gradients and an eddy current delay $t_{\mathrm{e}}$ of $5 \mathrm{~ms}$ was used [16].

The signal intensity (I) was monitored as a function of the square of the gradient amplitude $(g)$ and the resulting diffusion coefficients $(D)$ were calculated according to the Stejskal-Tanner equation

$I=I_{0} \exp \left[-D(\gamma \delta g)^{2}\left(\Delta-\frac{\delta}{3}-\frac{\tau_{\mathrm{g}}}{2}\right)\right]$

where $I_{0}$ is the intensity in the absence of gradient pulses, $\delta$ is the duration of the applied gradient, $\gamma$ is the gyromagnetic ratio of the nucleus, $\Delta$ is the diffusion time and $\tau_{g}$ is the gradient recovery delay.

Table 1

Densities and self-diffusion coefficients of pure compounds obtained by computer simulation in comparison with experimental data and their respective percent deviation.

\begin{tabular}{|c|c|c|c|c|c|c|}
\hline \multicolumn{7}{|c|}{ Heavy water } \\
\hline \multirow[t]{2}{*}{$T / \mathrm{K}$} & \multicolumn{3}{|l|}{$\rho\left(\mathrm{kg} / \mathrm{m}^{3}\right)$} & \multicolumn{3}{|c|}{$D \times 10^{9}\left(\mathrm{~m}^{2} / \mathrm{s}\right)$} \\
\hline & Simulation & Experiment & Deviation (\%) & Simulation & Experiment & Deviation (\%) \\
\hline 283.2 & $1111.7 \pm 0.1$ & $1106.7[33]$ & 0.52 & $1.28 \pm 0.03$ & $\begin{array}{l}1.14[34] \\
1.22[35] \\
1.21[36]\end{array}$ & $\begin{array}{l}12.0 \\
4.9 \\
5.8\end{array}$ \\
\hline 298.2 & $1108.5 \pm 0.1$ & $1104.5[33]$ & 0.36 & $1.91 \pm 0.02$ & $\begin{array}{l}1.80[34] \\
1.78[35] \\
1.76[36]\end{array}$ & $\begin{array}{l}6.1 \\
7.3 \\
8.5\end{array}$ \\
\hline 303.2 & $1106.7 \pm 0.1$ & $1103.3[33]$ & 0.31 & & & \\
\hline 313.2 & $1102.8 \pm 0.1$ & $1100.0[33]$ & 0.25 & $2.60 \pm 0.04$ & $\begin{array}{l}2.56[37] \\
2.50[35] \\
2.46[36]\end{array}$ & $\begin{array}{l}1.6 \\
4.0 \\
5.7\end{array}$ \\
\hline 318.2 & $1100.4 \pm 0.1$ & $1098.0[33]$ & 0.22 & & & \\
\hline 333.2 & $1092.0 \pm 0.1$ & $1090.6[33]$ & 0.13 & & & \\
\hline \multicolumn{7}{|c|}{ 2,2,3,3,4,4,5,5,5-Nonafluoropentan-1-ol } \\
\hline \multirow[t]{2}{*}{$T / \mathrm{K}$} & & $\rho\left(\mathrm{kg} / \mathrm{m}^{3}\right)$ & & & & \\
\hline & & Simulation & & Experiment & & Deviation (\%) \\
\hline 283.2 & & $1672 \pm 3$ & & $1680.2[38]$ & & -0.5 \\
\hline 298.2 & & $1640 \pm 2$ & & $1651.3[38]$ & & -0.7 \\
\hline 313.2 & & $1605 \pm 2$ & & $1621.2[38]$ & & -1.0 \\
\hline
\end{tabular}


The duration of the pulse gradients and the diffusion time were adjusted in order to obtain full attenuation of the signals at $95 \%$ of maximum gradient strength. Typically, the values used were 2$3 \mathrm{~ms}$ for the duration of the gradient pulses and $80-100 \mathrm{~ms}$ for the diffusion time. The gradient strength was incremented from $2 \%$ to $95 \%$ in a linear ramp with 16 steps. A delay of $15 \mathrm{~s}$ between echoes was used. The gradients were previously calibrated using $\mathrm{D}_{2} \mathrm{O}$ $99.9 \%$ as a standard [17].

Intra-diffusion coefficients of 2,2,3,3,3-pentafluoropropan-1-ol, 2,2,3,3,4,4,4-heptafluorobutan-1-ol and 2,2,3,3,4,4,5,5,5-nonafluoropentan-1-ol in water were measured as a function of composition in the solute infinite dilution limit at temperatures from 283.2 to $313.2 \mathrm{~K}$ with intervals of $5 \mathrm{~K}$. For comparison the intra-diffusion coefficients of 2,2,2-trifluoroethanol and 2,2,3,3,4,4,4-heptafluorobutan-1-ol were also measured in heavy water as a function of composition and at the same temperatures as above. Solutions were prepared by weight (with an uncertainty of $0.01 \mathrm{mg}$ ) in screw-cap flasks with 4 or $20 \mathrm{~mL}$, keeping the vapor phase to a minimum volume. The uncertainty in molar fractions was estimated to be $1 \times 10^{-6}$. The solutions were placed in capped $5 \mathrm{~mm}$ NMR tubes. For the solutions in normal water, a sealed capillary with $\mathrm{D}_{2} \mathrm{O}$ was inserted to provide for deuterium lock. In the case of the solutions in heavy water, the deuterium lock was provided by the solvent itself. Temperature was controlled by a BCU05 Bruker unit and measured to within $0.1 \mathrm{~K}$. The probe temperature was previously calibrated with a copper-constantan thermocouple placed inside the NMR tube.

\section{Simulation details}

\subsection{Models}

The optimized potentials for liquid simulations all-atom (OPLSAA) force-field [18] framework was used to model the fluorinated alcohols and 1-butanol as test substance. This force-field models each atom as an interaction site and the potential energy is written as the sum of contributions due to bond stretching, bond angle bending, dihedral angle torsion and non-bonded interactions (van der Waals plus electrostatic interactions). Water was modeled by the TIP4P/2005 force field developed by Abascal and Vega [19], which is a four-center rigid model based on TIP4P from Jorgensen et al. [20]. The model used for heavy water was obtained from that of normal water by simply replacing the mass of the hydrogen atoms by that of deuterium. Details about the exact expressions used for the potential terms can be found in the original references. All the parameters needed for the simulations are summarized in Tables 1-4 of Pereira et al. [15]. For 2,2,2-trifluoroethanol the parameters used were those obtained in the framework of OPLSAA by Duffy [21,22]. For the longer fluorinated alcohols studied here (HFB and NFP), Jorgensen et al. [18] (alcohol moieties) and Watkins et al. [23] (perfluoroalkyl moieties) parameters were used, along with the torsional functional form and parameters proposed by Pádua [24] for the cross-dihedral terms between fluorinated and hydrogenated parts of the carbon chain. The parameters proposed by Duffy were also tested in the alcohol moieties of the longer fluorinated alcohols without any significant improvement

Table 2

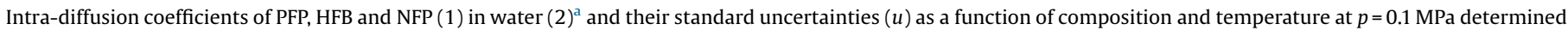
by PFG-NMR spin-echo technique.

\begin{tabular}{|c|c|c|c|c|c|c|c|c|}
\hline \multicolumn{9}{|c|}{ 2,2,3,3,3-Pentafluoropropan-1-ol } \\
\hline$T / \mathrm{K}$ & $\begin{array}{l}D_{1} \times 10^{9}\left(\mathrm{~m}^{2} / \mathrm{s}\right) \\
x_{1}=0.000500\end{array}$ & $u\left(\mathrm{D}_{1}\right) \times 10^{9}\left(\mathrm{~m}^{2} / \mathrm{s}\right)$ & $\begin{array}{l}\mathrm{D}_{1} \times 10^{9}\left(\mathrm{~m}^{2} / \mathrm{s}\right) \\
x_{1}=0.001003\end{array}$ & $u\left(\mathrm{D}_{1}\right) \times 10^{9}\left(\mathrm{~m}^{2} / \mathrm{s}\right)$ & $\begin{array}{l}D_{1} \times 10^{9}\left(\mathrm{~m}^{2} / \mathrm{s}\right) \\
x_{1}=0.004995\end{array}$ & $u\left(D_{1}\right) \times 10^{9}\left(\mathrm{~m}^{2} / \mathrm{s}\right)$ & $\begin{array}{l}D_{1} \times 10^{9}\left(\mathrm{~m}^{2} / \mathrm{s}\right) \\
x_{1}=0.009677\end{array}$ & $u\left(D_{1}\right) \times 10^{9}\left(\mathrm{~m}^{2} / \mathrm{s}\right)$ \\
\hline 283.2 & 0.617 & 0.001 & 0.615 & 0.001 & 0.576 & 0.001 & 0.534 & 0.001 \\
\hline 288.2 & 0.728 & 0.002 & 0.724 & 0.001 & 0.681 & 0.002 & 0.634 & 0.001 \\
\hline 293.2 & 0.845 & 0.003 & 0.839 & 0.002 & 0.792 & 0.002 & 0.745 & 0.001 \\
\hline 298.2 & 0.978 & 0.002 & 0.964 & 0.001 & 0.913 & 0.001 & 0.862 & 0.001 \\
\hline 303.2 & 1.127 & 0.003 & 1.111 & 0.001 & 1.048 & 0.001 & 0.990 & 0.001 \\
\hline 308.2 & 1.284 & 0.004 & 1.282 & 0.003 & 1.203 & 0.002 & 1.145 & 0.002 \\
\hline 313.2 & 1.462 & 0.004 & 1.486 & 0.005 & 1.371 & 0.003 & 1.295 & 0.003 \\
\hline \multicolumn{9}{|c|}{ 2,2,3,3,4,4,4-Heptafluorobutan-1-ol } \\
\hline$T / \mathrm{K}$ & $\begin{array}{l}D_{1} \times 10^{9}\left(\mathrm{~m}^{2} / \mathrm{s}\right) \\
x_{1}=0.000122\end{array}$ & $u\left(D_{1}\right) \times 10^{9}\left(\mathrm{~m}^{2} / \mathrm{s}\right)$ & $\begin{array}{l}D_{1} \times 10^{9}\left(\mathrm{~m}^{2} / \mathrm{s}\right) \\
x_{1}=0.000259\end{array}$ & $u\left(D_{1}\right) \times 10^{9}\left(\mathrm{~m}^{2} / \mathrm{s}\right)$ & $\begin{array}{l}D_{1} \times 10^{9}\left(\mathrm{~m}^{2} / \mathrm{s}\right) \\
x_{1}=0.000506\end{array}$ & $u\left(D_{1}\right) \times 10^{9}\left(\mathrm{~m}^{2} / \mathrm{s}\right)$ & $\begin{array}{l}D_{1} \times 10^{9}\left(\mathrm{~m}^{2} / \mathrm{s}\right) \\
x_{1}=0.000988\end{array}$ & $u\left(D_{1}\right) \times 10^{9}\left(\mathrm{~m}^{2} / \mathrm{s}\right)$ \\
\hline 283.2 & 0.554 & 0.004 & 0.552 & 0.003 & 0.553 & 0.001 & 0.547 & 0.002 \\
\hline 288.2 & 0.650 & 0.005 & 0.651 & 0.003 & 0.649 & 0.004 & 0.644 & 0.001 \\
\hline 293.2 & 0.762 & 0.006 & 0.768 & 0.003 & 0.763 & 0.002 & 0.754 & 0.001 \\
\hline 298.2 & 0.88 & 0.01 & 0.884 & 0.003 & 0.876 & 0.001 & 0.866 & 0.001 \\
\hline 303.2 & 1.00 & 0.01 & 1.009 & 0.004 & 1.001 & 0.002 & 0.996 & 0.003 \\
\hline 308.2 & 1.17 & 0.01 & 1.158 & 0.006 & 1.154 & 0.003 & 1.130 & 0.002 \\
\hline 313.2 & 1.34 & 0.03 & 1.362 & 0.006 & 1.323 & 0.003 & 1.294 & 0.003 \\
\hline \multicolumn{9}{|c|}{$2,2,3,3,4,4,5,5,5$-Nonafluoropentan-1-ol } \\
\hline$T / \mathrm{K}$ & & $\begin{array}{l}D_{1} \times 10^{9}\left(\mathrm{~m}^{2} / \mathrm{s}\right) \\
x_{1}=0.000054\end{array}$ & & $u\left(D_{1}\right) \times 10^{9}\left(\mathrm{~m}^{2} / \mathrm{s}\right)$ & & $\begin{array}{l}D_{1} \times 10^{9}\left(\mathrm{~m}^{2} / \mathrm{s}\right) \\
x_{1}=0.000104\end{array}$ & & $u\left(D_{1}\right) \times 10^{9}\left(\mathrm{~m}^{2} / \mathrm{s}\right)$ \\
\hline 283.2 & & 0.51 & & 0.02 & & 0.51 & & 0.01 \\
\hline 288.2 & & 0.61 & & 0.03 & & 0.60 & & 0.01 \\
\hline 293.2 & & 0.70 & & 0.02 & & 0.70 & & 0.01 \\
\hline 298.2 & & 0.81 & & 0.03 & & 0.81 & & 0.01 \\
\hline 303.2 & & 0.94 & & 0.03 & & 0.92 & & 0.01 \\
\hline 308.2 & & 1.07 & & 0.03 & & 1.06 & & 0.01 \\
\hline 313.2 & & 1.24 & & 0.03 & & 1.23 & & 0.01 \\
\hline
\end{tabular}

a Standard uncertainty for temperature: $u(T)=0.1 \mathrm{~K}$. 
Table 3

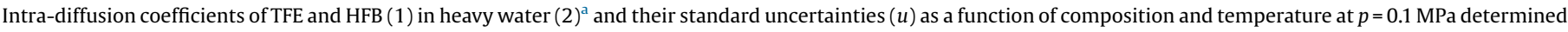
by PFG-NMR spin-echo technique.

\begin{tabular}{|c|c|c|c|c|c|c|}
\hline \multicolumn{7}{|c|}{ 2,2,2-Trifluoroethanol } \\
\hline$T / \mathrm{K}$ & $\begin{array}{l}D_{1} \times 10^{9}\left(\mathrm{~m}^{2} / \mathrm{s}\right) \\
x_{1}=0.001011\end{array}$ & $u\left(D_{1}\right) \times 10^{9}\left(\mathrm{~m}^{2} / \mathrm{s}\right)$ & $\begin{array}{l}D_{1} \times 10^{9}\left(\mathrm{~m}^{2} / \mathrm{s}\right) \\
x_{1}=0.005038\end{array}$ & $u\left(D_{1}\right) \times 10^{9}\left(\mathrm{~m}^{2} / \mathrm{s}\right)$ & $\begin{array}{l}D_{1} \times 10^{9}\left(\mathrm{~m}^{2} / \mathrm{s}\right) \\
x_{1}=0.009657\end{array}$ & $u\left(D_{1}\right) \times 10^{9}\left(\mathrm{~m}^{2} / \mathrm{s}\right)$ \\
\hline 283.2 & 0.568 & 0.001 & 0.549 & 0.001 & 0.527 & 0.001 \\
\hline 288.2 & 0.664 & 0.001 & 0.646 & 0.001 & 0.640 & 0.001 \\
\hline 293.2 & 0.780 & 0.002 & 0.754 & 0.001 & 0.755 & 0.002 \\
\hline 298.2 & 0.901 & 0.003 & 0.866 & 0.002 & 0.869 & 0.003 \\
\hline 303.2 & 1.024 & 0.003 & 0.989 & 0.003 & 0.986 & 0.004 \\
\hline 308.2 & 1.159 & 0.003 & 1.119 & 0.003 & 1.155 & 0.007 \\
\hline 313.2 & 1.306 & 0.003 & 1.275 & 0.003 & & \\
\hline \multicolumn{7}{|c|}{ 2,2,3,3,4,4,4-Heptafluorobutan-1-ol } \\
\hline$T / \mathrm{K}$ & $D_{1} \times 10^{9}\left(\mathrm{~m}^{2} / \mathrm{s}\right)$ & $u\left(D_{1}\right) \times 10^{9}\left(\mathrm{~m}^{2} / \mathrm{s}\right)$ & $D_{1} \times 10^{9}\left(\mathrm{~m}^{2} / \mathrm{s}\right)$ & $u\left(D_{1}\right) \times 10^{9}\left(\mathrm{~m}^{2} / \mathrm{s}\right)$ & $D_{1} \times 10^{9}\left(\mathrm{~m}^{2} / \mathrm{s}\right)$ & $u\left(D_{1}\right) \times 10^{9}\left(\mathrm{~m}^{2} / \mathrm{s}\right)$ \\
\hline & $x_{1}=0.000124$ & & $x_{1}=0.000257$ & & $x_{1}=0.000980$ & \\
\hline 283.2 & 0.430 & 0.001 & 0.429 & 0.001 & 0.425 & 0.001 \\
\hline 288.2 & 0.509 & 0.001 & 0.501 & 0.001 & 0.501 & 0.001 \\
\hline 293.2 & 0.594 & 0.001 & 0.599 & 0.001 & 0.588 & 0.002 \\
\hline 298.2 & 0.687 & 0.002 & 0.691 & 0.002 & 0.688 & 0.002 \\
\hline 303.2 & 0.786 & 0.001 & 0.780 & 0.003 & 0.810 & 0.002 \\
\hline 308.2 & 0.892 & 0.003 & 0.889 & 0.002 & 0.992 & 0.002 \\
\hline 313.2 & 1.004 & 0.004 & 1.030 & 0.003 & 1.202 & 0.003 \\
\hline
\end{tabular}

a Standard uncertainty for temperature: $u(T)=0.1 \mathrm{~K}$.

Table 4

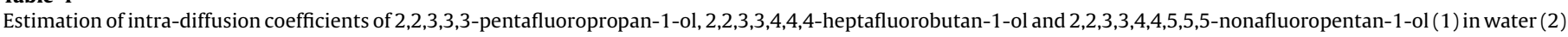
at infinite dilution and their standard uncertainties.

\begin{tabular}{|c|c|c|c|c|c|c|}
\hline \multirow[t]{2}{*}{$T / \mathrm{K}$} & \multicolumn{2}{|l|}{ PFP } & \multicolumn{2}{|l|}{ HFB } & \multicolumn{2}{|l|}{ NFP } \\
\hline & $D_{1}^{\infty} \cdot 109(\mathrm{~m} 2 / \mathrm{s})$ & $u\left(D_{1}^{\infty}\right) \times 10^{9}\left(\mathrm{~m}^{2} / \mathrm{s}\right)$ & $D_{1}^{\infty} \times 10^{9}\left(\mathrm{~m}^{2} / \mathrm{s}\right)$ & $u\left(D_{1}^{\infty}\right) \times 10^{9}\left(\mathrm{~m}^{2} / \mathrm{s}\right)$ & $D_{1}^{\infty} \times 10^{9}\left(\mathrm{~m}^{2} / \mathrm{s}\right)$ & $u\left(D_{1}^{\infty}\right) \times 10^{9}\left(\mathrm{~m}^{2} / \mathrm{s}\right)$ \\
\hline 283.2 & 0.623 & 0.002 & 0.553 & 0.004 & 0.52 & 0.04 \\
\hline 288.2 & 0.734 & 0.001 & 0.650 & 0.001 & 0.61 & 0.03 \\
\hline 293.2 & 0.852 & 0.001 & 0.761 & 0.006 & 0.70 & 0.02 \\
\hline 298.2 & 0.984 & 0.004 & 0.886 & 0.005 & 0.81 & 0.03 \\
\hline 303.2 & 1.134 & 0.005 & 1.005 & 0.008 & 0.95 & 0.08 \\
\hline 308.2 & 1.299 & 0.006 & 1.171 & 0.009 & 1.08 & 0.07 \\
\hline 313.2 & 1.49 & 0.03 & 1.35 & 0.03 & 1.25 & 0.08 \\
\hline
\end{tabular}

in the description of the systems. In that case atomic charges of PFP, HFB and NFP were evaluated by quantum mechanical calculations at the MP2/cc-pVTZ//HF/6-31G(d) level of theory, with the partial charges obtained by the Kollman and Singh scheme [25]; all quantum calculations were performed using the GAMESS-US package [26].

Following the OPLS-AA parameterization, geometrical combining rules were used to compute the non-bonded Lennard-Jones interactions between sites of different types:

$\varepsilon_{i j}=\sqrt{\varepsilon_{i i} \varepsilon_{j j}}$

$\sigma_{i j}=\sqrt{\sigma_{i i} \sigma_{j j}}$

For non-bonded interactions between sites in the same molecule, only sites separated by three or more bonds are considered. Nonbonded interactions between sites separated by three bonds are scaled by a factor of 0.5 . In this work, all bonds involving hydrogen were treated as rigid, with the respective length fixed at the equilibrium distance, and the LINCS [27] algorithm was used to constrain them.

\subsection{Methods}

Molecular dynamics simulations were performed using the GROMACS package [28,29], with systems of 1000 total molecules, to which periodic boundary conditions were applied in three directions. The initial liquid box sizes were established according to the experimental densities. For each system, the following simulation protocol was applied: an initial NpT equilibration run of $2 \mathrm{~ns}$ followed by a $10 \mathrm{~ns}$ long $N p T$ production run from which the density of the system could be calculated; then a $1 \mathrm{~ns} N V T$ equilibration run followed by a $10 \mathrm{~ns} N V T$ production run, whose trajectories were used to compute the diffusion coefficients of solutes in water. Before doing the NVT simulations, the box volume was adjusted to the average value of the $N p T$ production run. The equations of motion were solved using the leapfrog integration algorithm, with a time step of $1 \mathrm{fs}$. In the equilibration runs the Berendsen thermostat and barostat [30] (the latter only in $N p T$ ensembles) was used, whereas in the production runs, temperature was controlled using the Nosé-Hoover thermostat [31] and pressure (in NpT ensemble) was controlled by the Parrinello-Rahman barostat [32]. For temperature control, coupling constants of 0.03 and 0.1 ps were used for Berendsen and Nosé-Hoover thermostats, respectively. In the case of pressure, coupling constants of 4.0 and 1.0 ps were used respectively in the Berendsen and Parrinello-Rahman barostats. An initial velocity obtained from a Maxwell distribution at the desired initial temperature has been assigned to all atoms.

In all simulations a neighbor list, with a radius of $10 \AA$, was used and was updated every 5 time steps. Both non-bonded LennardJones and electrostatic potential were truncated by using cut-offs of $12 \AA$ and $10 \AA$, respectively and analytical tail corrections to dispersion terms were added. The long-range electrostatic 
(coulombic) interactions beyond the cutoff were calculated using the particle-mesh Ewald method. Before the molecular dynamics runs, the boxes were subjected to energy minimization by the steepest descent method to a maximum force of $10 \mathrm{~kJ} / \mathrm{mol} \mathrm{nm}$, with a maximum number of steps of $1 \times 10^{5}$.For each state point and system, a total of 20 independent simulation sequences were performed each one starting from a different initial configuration. The final value of diffusion coefficient was calculated as the average of the 20 values obtained independently for each state point.

\subsection{Calculations}

The intra-diffusion coefficients of different solutes in water $\left(D_{1}\right)$ were calculated from the linear part of the mean square displacement of the center of mass of the solute molecules according to the Einstein equation:

$D_{1}=\frac{1}{6 N} t \rightarrow \infty \frac{\mathrm{d}}{\mathrm{d} t} \sum_{i=1}^{N}\left\langle\left[r_{i}(t)-r_{i}(0)\right]^{2}\right\rangle$

where $\left[r_{i}(t)-r_{i}(0)\right]^{2}$ is the mean square displacement of the solute and the \langle\rangle brackets stand for average over time. The summation extends to all solute molecules in the simulation box.

Three different binary systems have been studied by MD simulation: 2,2,3,3,4,4,5,5,5-nonafluoropentan-1-ol (NFP) in water and 2,2,2-trifluoroethanol (TFE) and 2,2,3,3,4,4,4-heptafluorobutan-1-nol (HFB) both in normal and heavy water. The binary system 1-butanol/water was also examined for comparison purposes. The TFE $/ \mathrm{D}_{2} \mathrm{O}$ system was simulated at two different compositions (alcohol mole fractions, $x_{1}$, of 0.001 and 0.005 ) while the remaining systems were studied at just one composition $\left(x_{1}=\right.$ 0.001 ) due to the low solubility of these alcohols in water. A total of 1000 molecules were placed inside the simulation box, comprising 1 solute and 999 water molecules for $x_{1}=0.001$ and 5 solute with 995 water molecules for $x_{1}=0.005$. For the 0.001 mole fraction, since a single solute molecule was present, the mixtures can be considered at infinite dilution limit. In the case of the systems involving NFP, due to their low solubility, only the proportion 1/ 999 for solute/water molecules was studied, assuming an infinite dilution behavior for that condition. All binary mixtures were studied at three different temperatures: 283.2, 298.2 and $313.2 \mathrm{~K}$.

\subsection{Pure component results}

In order to test the suitability of the molecular models used, pure liquid $\mathrm{D}_{2} \mathrm{O}$ and NFP were also simulated. The liquid densities of these two substances and also the self-diffusion coefficients of heavy water are reported and compared with experimental data from the literature in Table 1 . The agreement with the experimental densities is very good for both heavy water and NFP (better than $0.5 \%$ and $1.0 \%$, respectively) at all temperatures, and the selfdiffusion coefficients of $\mathrm{D}_{2} \mathrm{O}$ are also reasonably described, with deviations between 1.6 and $12 \%$ depending on temperature and on which experimental value is chosen to compare with.

\section{Results and discussion}

\subsection{Diffusion coefficients}

The experimental intra-diffusion coefficients of 2,2,3,3,3pentafluoropropan-1-ol, 2,2,3,3,4,4,4-heptafluorobutan-1-ol and $2,2,3,3,4,4,5,5,5$-nonafluoropentan-1-ol in water as a function of composition and temperature are presented in Table 2 and shown in Figs. 1-3 respectively. Those for 2,2,2-trifluoroethanol and $2,2,3,3,4,4,4$-heptafluorobutan-1-ol in heavy water are presented in Table 3 and shown in Figs. 4 and 5. For both solvents, the intradiffusion coefficients were fitted to polynomial functions at each temperature as a function of composition (when that was possible and relevant) and an estimation of the diffusion coefficients at infinite dilution was obtained. These are presented in Tables 4 and 5.

As far as we know, these are the first intra-diffusion coefficients of aqueous solutions of PFP, HFB and NFP reported in literature as well as the first data for HFB in heavy water.

Intra-diffusion coefficients of all these solutes increase slightly as their concentration decreases both in water and heavy water reflecting the unique structure of water as we stressed elsewhere [15] where the TFE/water behavior was analyzed. Deviations to this trend were found for HFB in heavy water and NFP in water, probably due to dispersion of the results. In these cases, the solute mole fractions are very low and the differences in diffusion coefficients for consecutive compositions are quite small.

As expected, the diffusion coefficients of the $n$-fluoroalcohols studied decrease regularly with the increasing chain length along the analogous series. In Fig. 6 the intra-diffusion coefficients of TFE

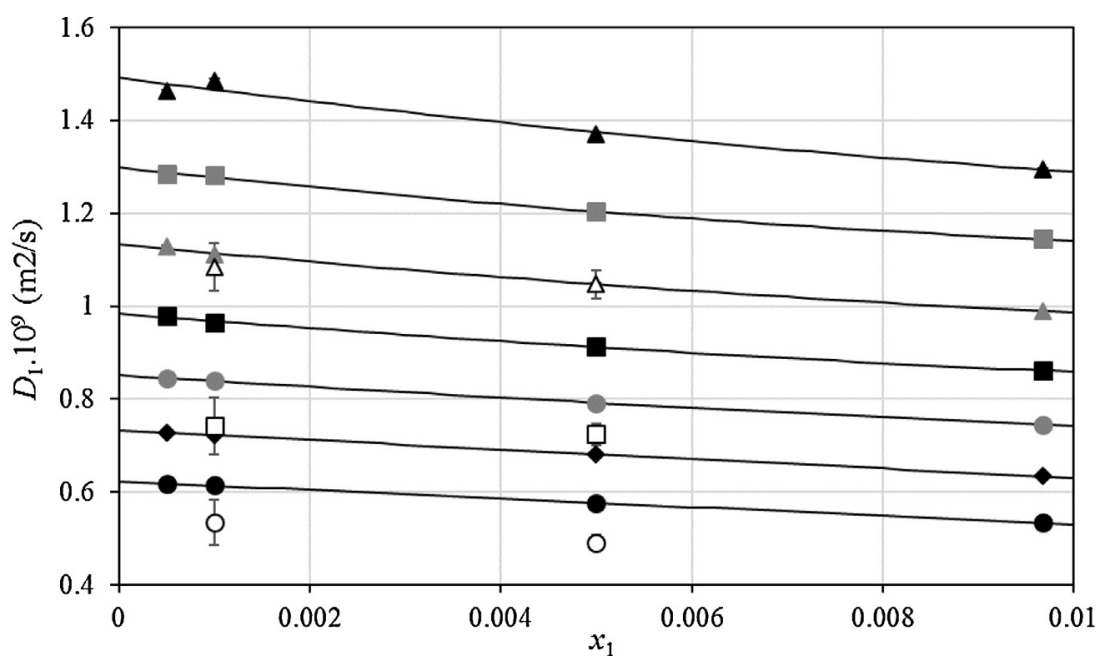

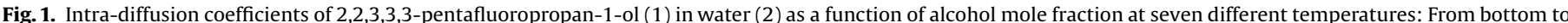

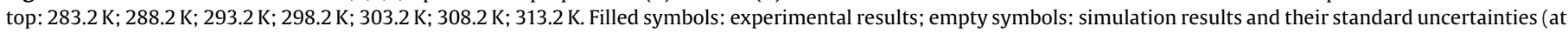
$283.2 \mathrm{~K}, 298.2 \mathrm{~K}$ and $313.2 \mathrm{~K}$, Ref. [15]). Lines: polynomial fittings to the experimental results. 


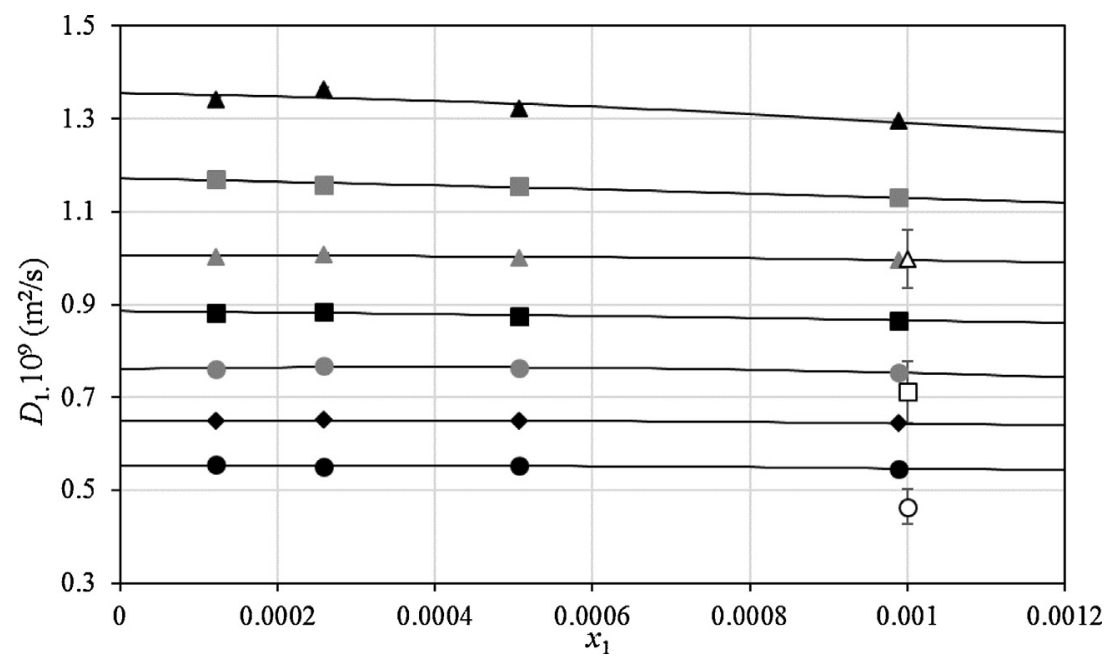

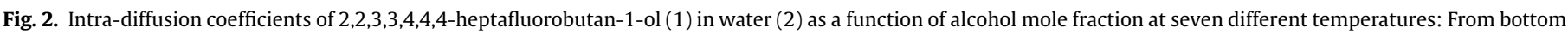

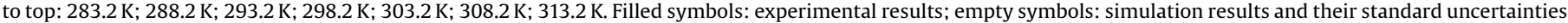
(at $283.2 \mathrm{~K}, 298.2 \mathrm{~K}$ and $313.2 \mathrm{~K}$, Ref. [15]). Lines: polynomial fittings to the experimental results.

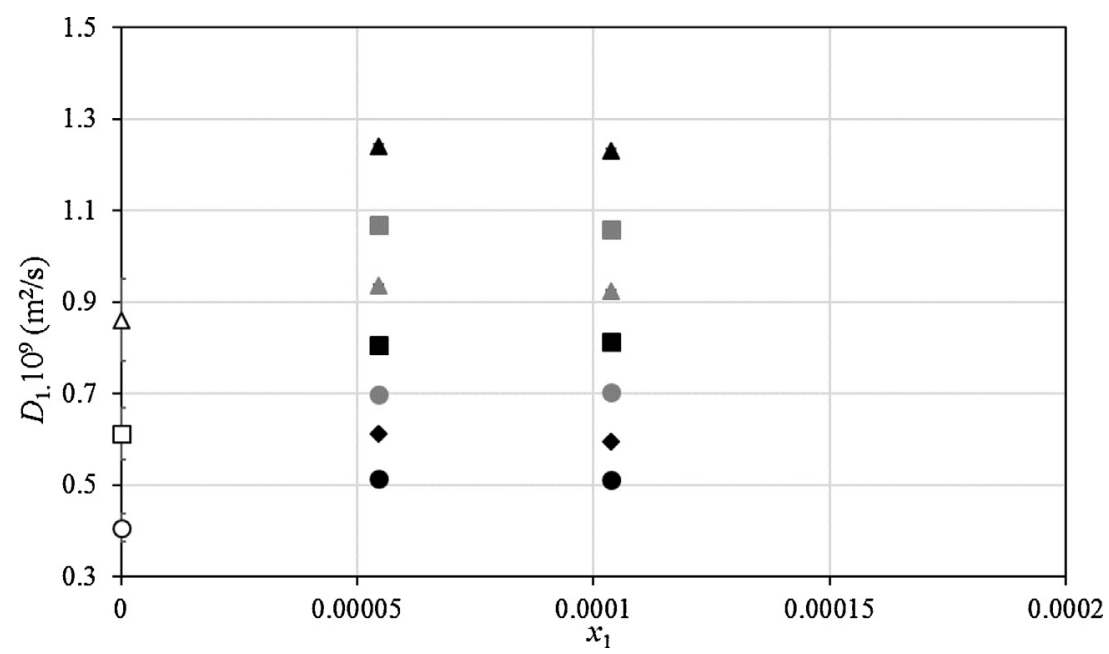

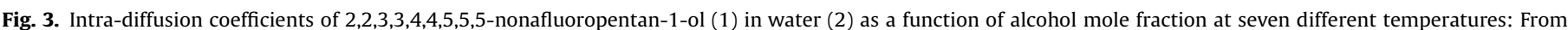

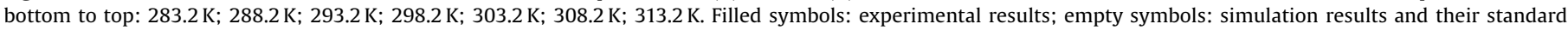
uncertainties (at $283.2 \mathrm{~K}, 298.2 \mathrm{~K}$ and $313.2 \mathrm{~K}$ ).

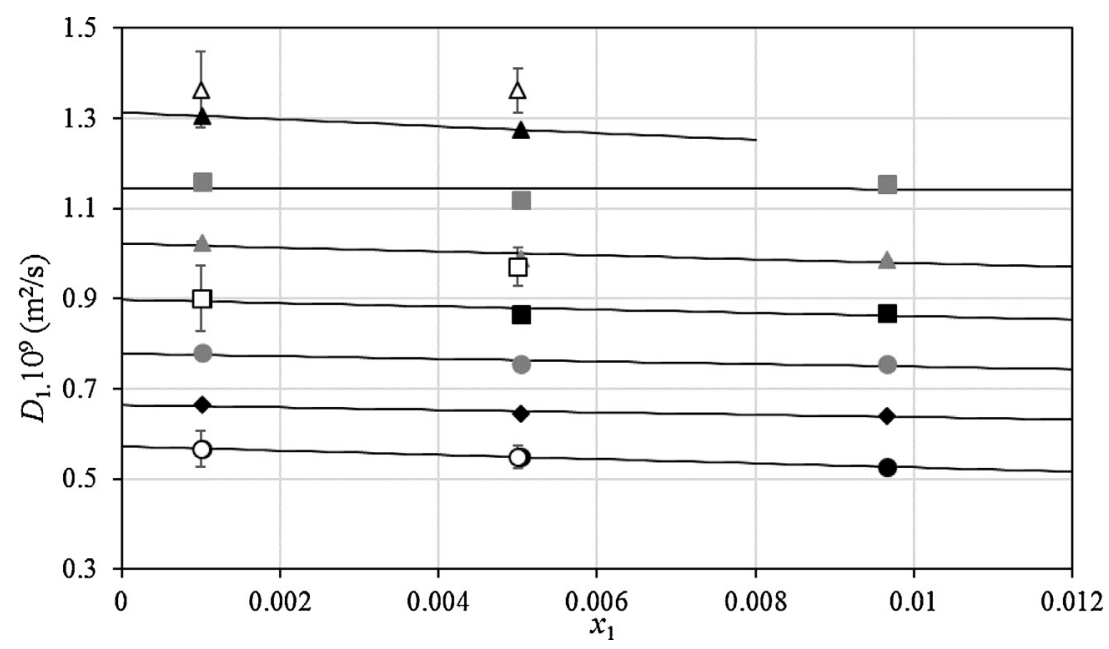

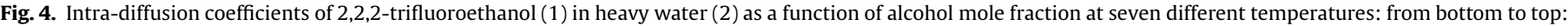

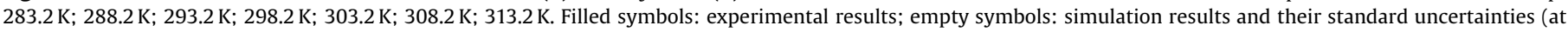
$283.2 \mathrm{~K}, 298.2 \mathrm{~K}$ and $313.2 \mathrm{~K}$ ). Lines: polynomial fittings to the experimental results. 


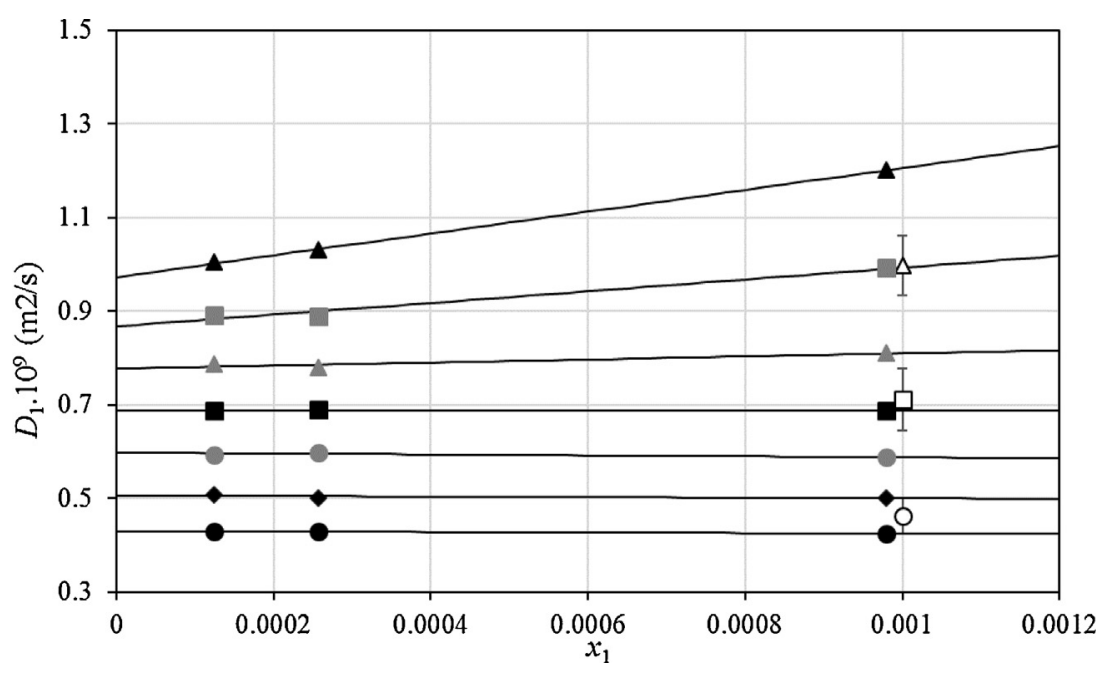

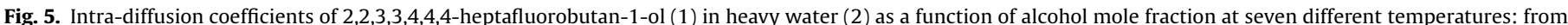

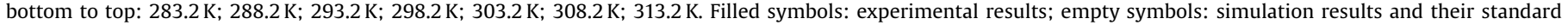
uncertainties (at $283.2 \mathrm{~K}, 298.2 \mathrm{~K}$ and $313.2 \mathrm{~K}$ ). Lines: polynomial fittings to the experimental results.

Table 5

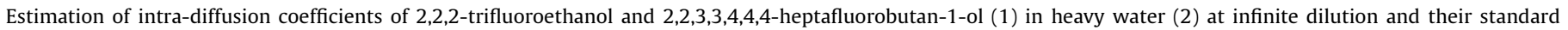
uncertainties.

\begin{tabular}{|c|c|c|c|c|}
\hline \multirow[t]{2}{*}{$T / \mathrm{K}$} & \multicolumn{2}{|l|}{ TFE } & \multicolumn{2}{|l|}{ HFB } \\
\hline & $D_{1}^{\infty} \times 10^{9}\left(\mathrm{~m}^{2} / \mathrm{s}\right)$ & $u\left(D_{1}^{\infty}\right) \times 10^{9}\left(\mathrm{~m}^{2} / \mathrm{s}\right)$ & $D_{1}^{\infty} \times 10^{9}\left(\mathrm{~m}^{2} / \mathrm{s}\right)$ & $u\left(D_{1}^{\infty}\right) \times 10^{9}\left(\mathrm{~m}^{2} / \mathrm{s}\right)$ \\
\hline 283.2 & 0.572 & 0.001 & 0.43 & 0.01 \\
\hline 288.2 & 0.664 & 0.001 & 0.51 & 0.02 \\
\hline 293.2 & 0.78 & 0.01 & 0.60 & 0.02 \\
\hline 298.2 & 0.898 & 0.003 & 0.69 & 0.03 \\
\hline 303.2 & 1.022 & 0.003 & 0.78 & 0.04 \\
\hline 308.2 & 1.15 & 0.03 & 0.87 & 0.06 \\
\hline 313.2 & 1.31 & 0.01 & 0.97 & 0.08 \\
\hline
\end{tabular}

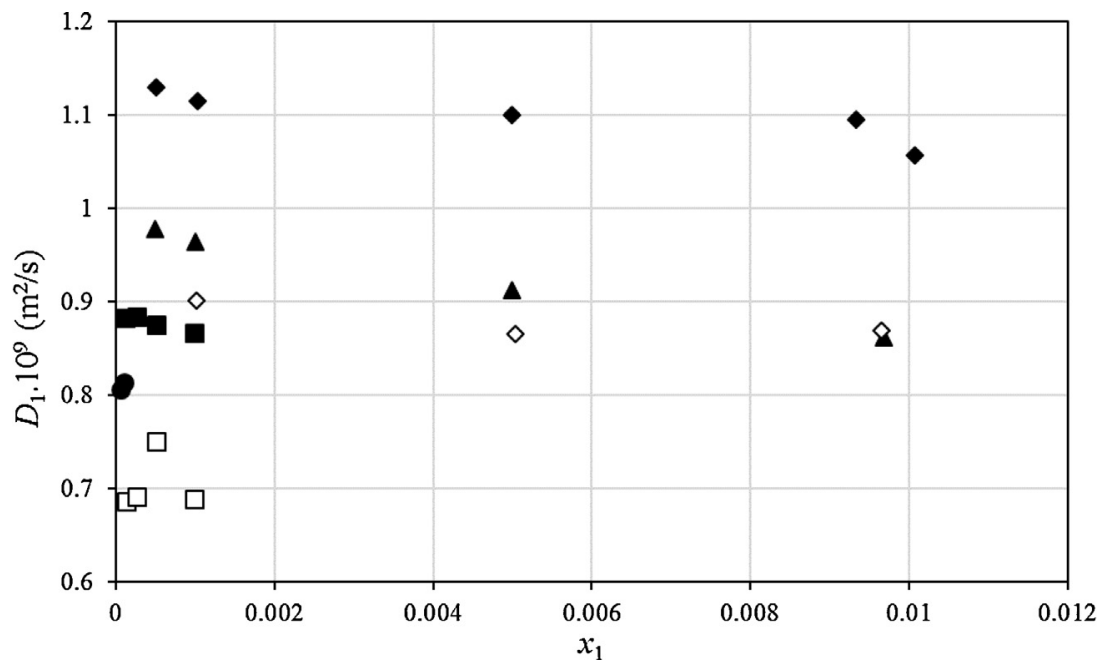

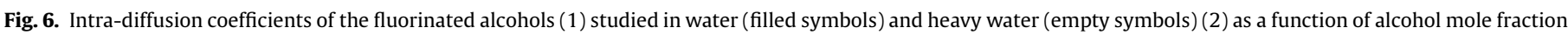
at $298.15 \mathrm{~K}$. Diamonds, TFE; triangles, PFP; squares, HFB; circles, NFP.

(from Ref. [15]), PFP, HFB and NFP in water at $298.2 \mathrm{~K}$ are shown, while the infinite dilution diffusion coefficients (strictly its natural logarithm) at all the temperatures as a function of number of carbon atoms are presented in Fig. 7, showing a fairly linear relation for each temperature.

A comparison of diffusion coefficients in water between hydrogenated and fluorinated alcohols is shown in Fig. 8. As could be expected considering the differences in molecular weight, the diffusion coefficients of each $n$-fluoroalcohol in water is lower than that of its hydrogenated counterpart (7.9\%, 6.3\%, 6.4\% and 8.8\% for 2, 3, 4 and 5 carbon atoms respectively, at infinite dilution). As can be seen, the diffusion coefficient of PFP is close to that of 1-butanol, while the diffusion coefficient of HFB is close to that of 1 -pentanol. However molecular weight is not the only factor 


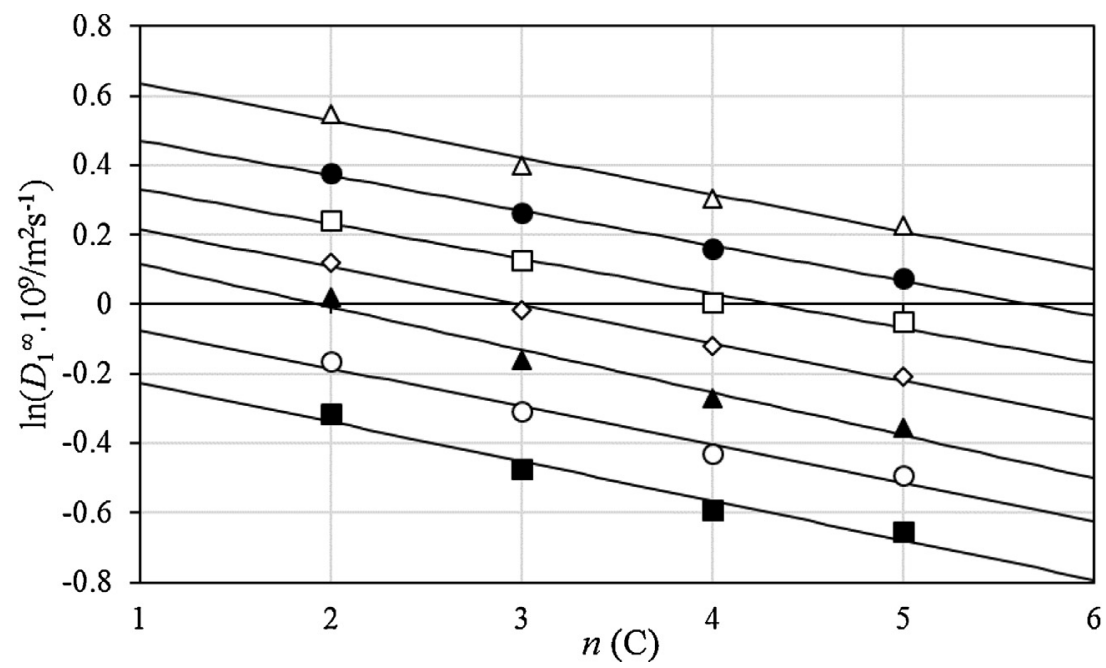

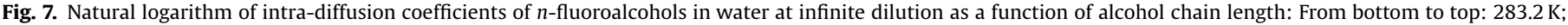
288.2 K; 293.2 K; 298.2 K; 303.2 K; 308.2 K; 313.2 K. Points: experimental results; lines: linear regressions.

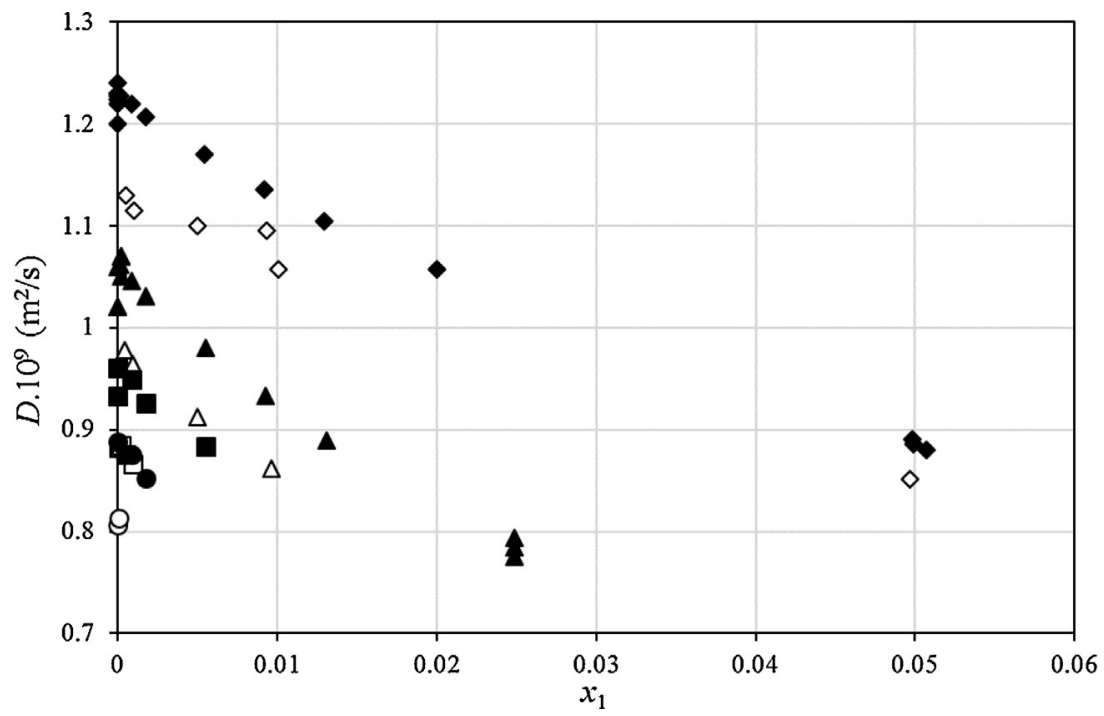

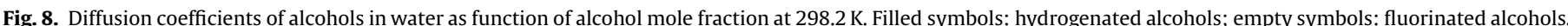

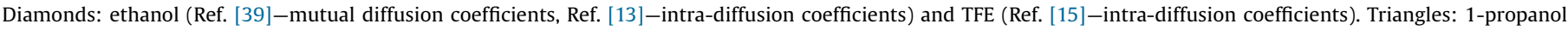

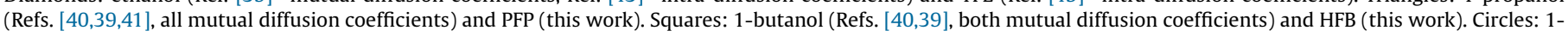
pentanol (Ref. [39]) and NFP (this work).

influencing the relative magnitudes of molecular mobility of these two chemical families. In Fig. 9, diffusion coefficients in water for fluorinated and hydrogenated alcohols are plotted against the inverse of the square root of solute molecular weight. Although there is a linear relation between the diffusion coefficient in water and the solute $M_{m}{ }^{-1 / 2}$ for both families, fluorinated and hydrogenated alcohols fall in two different lines, which is a clear indication that other factors besides molecular weight influence the mobility of these molecules in water. Interestingly, fluorinated alcohols display higher diffusion coefficients than hydrogenated alcohols with the same molecular weight. It is likely that the more hydrophobic nature of fluoroalkyl chain is one of the reasons for their higher mobility due to weaker interactions with the solvent.

Harris et al. [13] found a linear universal relation between $\ln$ $\left(D^{\infty}\right)$ of alcohols (including those primary, secondary and tertiary, linear and branched and with different chain lengths) in water and the logarithm of their partial molar volumes at infinite dilution, which also included the result of TFE. In Fig. 10, we have plotted In $\left(D^{\infty}\right)$ vs. In $\left(V_{\varphi, 1}^{\infty}\right)$ for the two families: the studied $n$-fluoroalcohols and their hydrogenated counterparts. For PFP, HFB and NFP we used partial molar volumes at infinite dilution recently measured in our laboratory [42], those obtained by Minamihonoki et al. [43] for TFE, and the data from Jolicoeur and Lacroix [44] for the hydrogenated alcohols, all in water at $298.2 \mathrm{~K}$. As can be seen, the results of both chemical families seem to fall on the same straight line, with a slope of -0.43 , showing that the main factors influencing the mobility in water (interaction with water and liquid packing) are captured by the behavior of the partial molar volumes.

Intra-diffusion coefficients of fluorinated alcohols in heavy water are also compared with those in normal water in Fig. 6, where it is apparent that the former are lower than the latter. This difference can be explained by the fact that heavy water presents higher values of viscosity than normal water, which by the StokesEinstein-Sutherland relation, results in lower diffusion coefficients. In fact the ratio $D^{\infty}{ }_{1}\left(\right.$ in $\left.\mathrm{D}_{2} \mathrm{O}\right) / D^{\infty}{ }_{1}\left(\right.$ in $\left.\mathrm{H}_{2} \mathrm{O}\right)$ has almost the same average value ( 0.78 and 0.76 ) both for TFE and HFB, whereas the ratio, $\eta_{\mathrm{H}_{2} \mathrm{O}} / \eta_{\mathrm{D}_{2} \mathrm{O}}[33]$, is 0.81 . Moreover, for each solute, the 


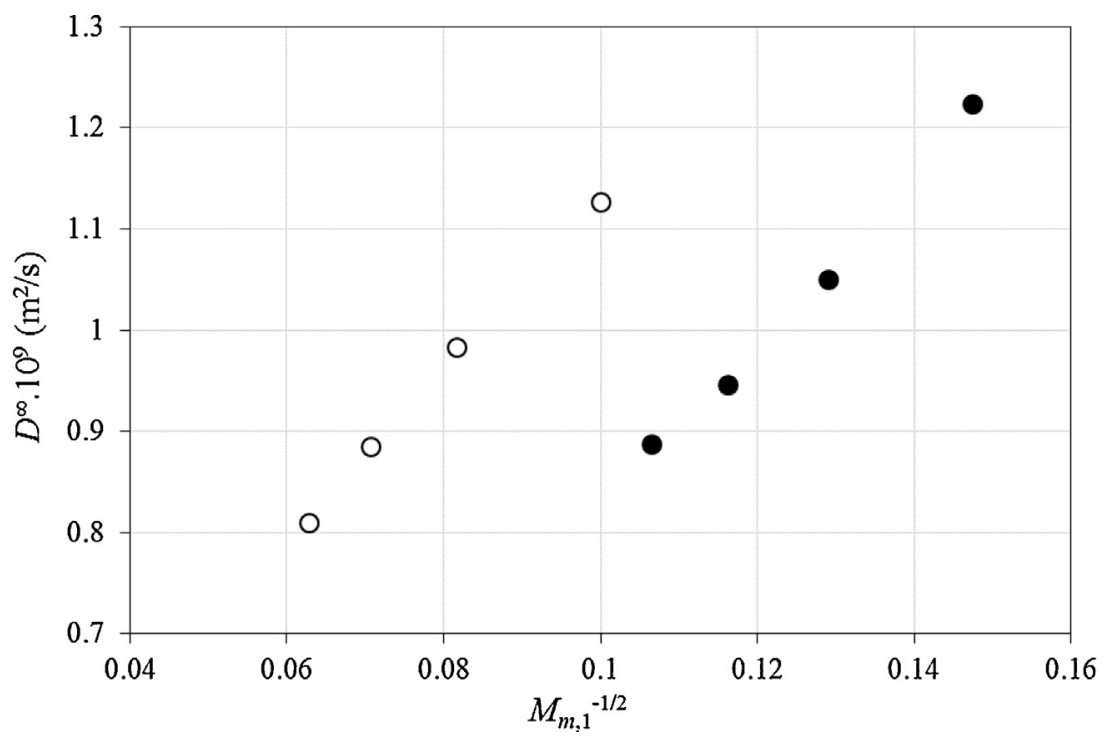

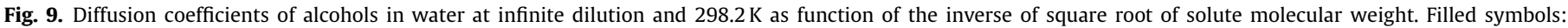
hydrogenated alcohols; empty symbols: fluorinated alcohols.

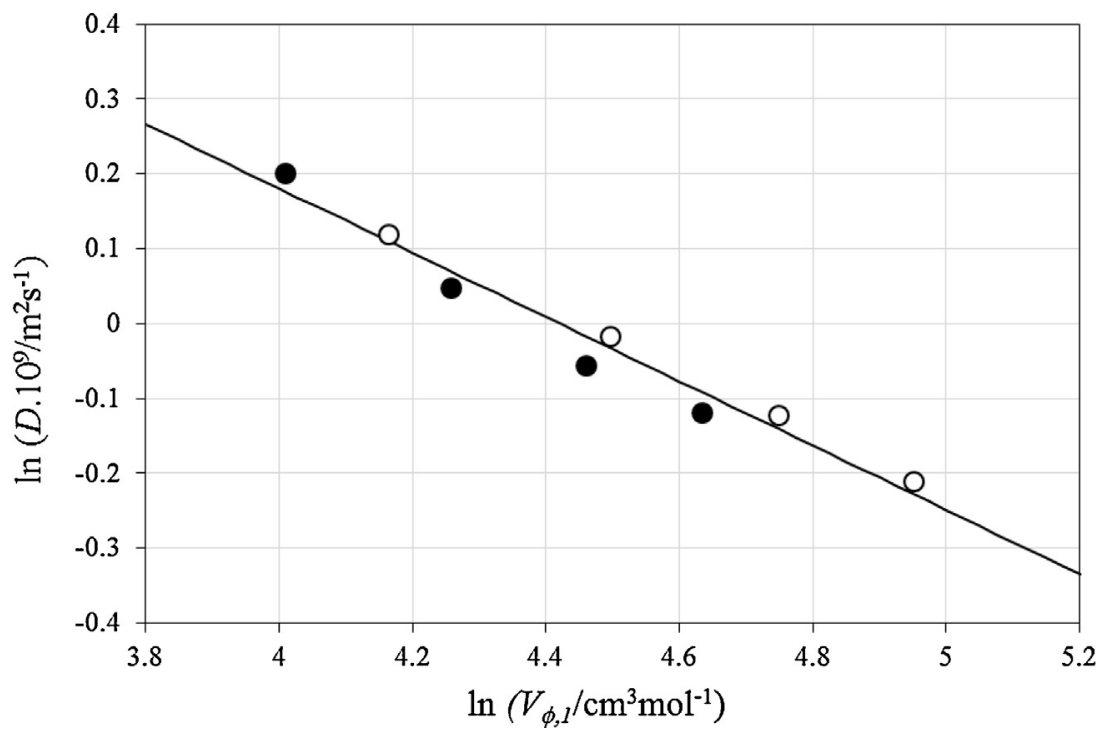

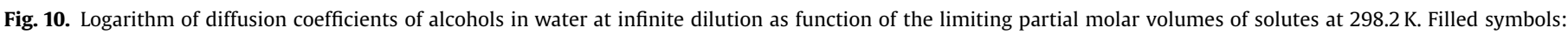
hydrogenated alcohols; empty symbols: fluorinated alcohols. Line: linear fitting of all the results.

parameter $\left(D^{\infty}{ }_{1} \eta / T\right)$ is fairly constant with temperature and similar for both solvents, with average values of $3.36 \times 10^{-15} \mathrm{~kg} \mathrm{~m} \mathrm{~s}^{-2} \mathrm{~K}^{-1}$ (TFE) and $2.58 \times 10^{-15} \mathrm{~kg} \mathrm{~m} \mathrm{~s}^{-2} \mathrm{~K}^{-1}$ (HFB) which are explained by the differences in solute molar volumes, as suggested by the Wilke-Chang relation [45].

\subsection{Diffusion activation energies}

From the measured intra-diffusion coefficients at different temperatures, the average diffusion activation energies within the 283-313 K temperature range has been calculated for all systems, assuming an Arrhenius-like behavior of the diffusion as:

$D_{1}=A_{D} \exp \left(\frac{-E_{D}}{R T}\right)$

here $A_{D}$ is a pre-exponential factor and $E_{D}$ is the activation energy of diffusion. The results are shown in Fig. 11 as a function of composition. The results of TFE in water from Ref. [15] were also included for comparison.

As can be seen, the diffusion activation energies of all $n$ fluoroalcohols are very similar, although a slight increase with molecular weight can be identified. In particular, the values for TFE seem to be slightly lower in this composition range, although the differences are practically within the estimated uncertainty. As for the dependence on composition the diffusion activation energies are essentially constant. As mentioned in the previous article of this series, the diffusion activation energy for TFE is also constant below $x_{1}=0.01$, increasing steeply for $x_{1}=0.05$.

The diffusion activation energies of fluorinated and hydrogenated $n$-alcohols are compared in Fig. 12. $E_{D}$ for TFE and ethanol are essentially the same, while those of fluorinated alcohols with 3 and 4 carbon atoms seem to be slightly higher than those of their hydrogenated analogues. 


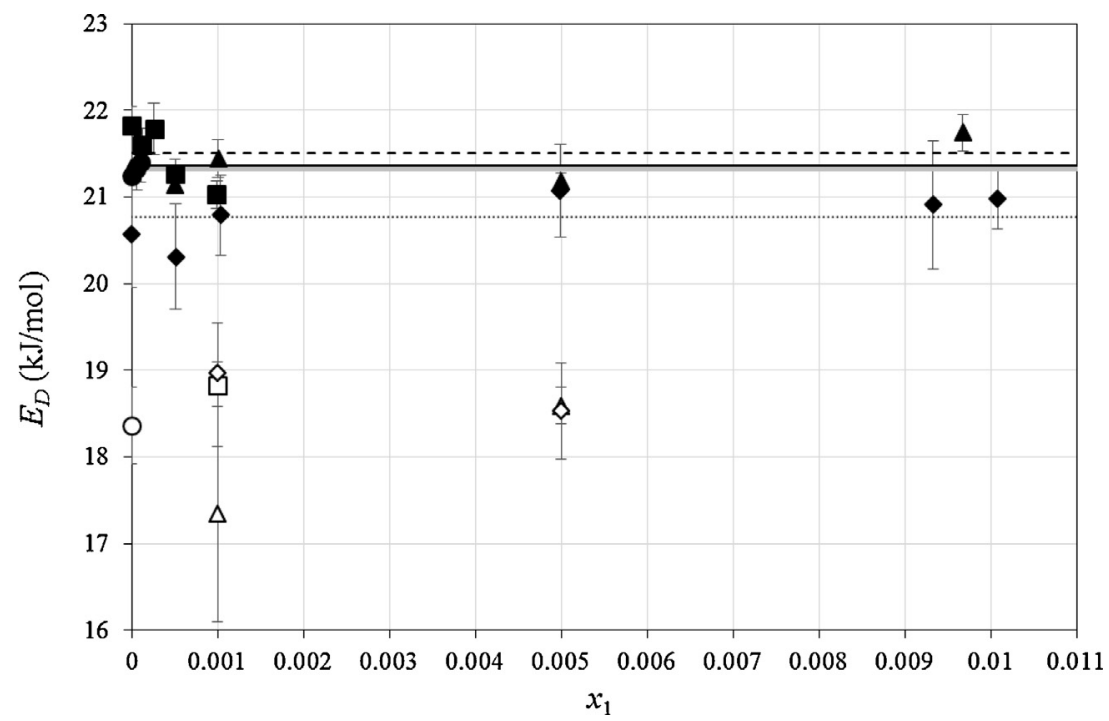

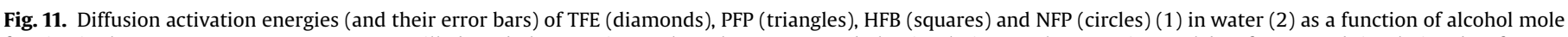

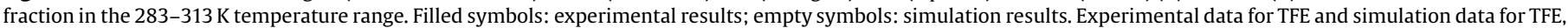
PFP and HFB from Ref. [15]. Lines: average values of diffusion activation energies for TFE (dotted), PFP (solid), HFB (dashed) NFP (large gray).

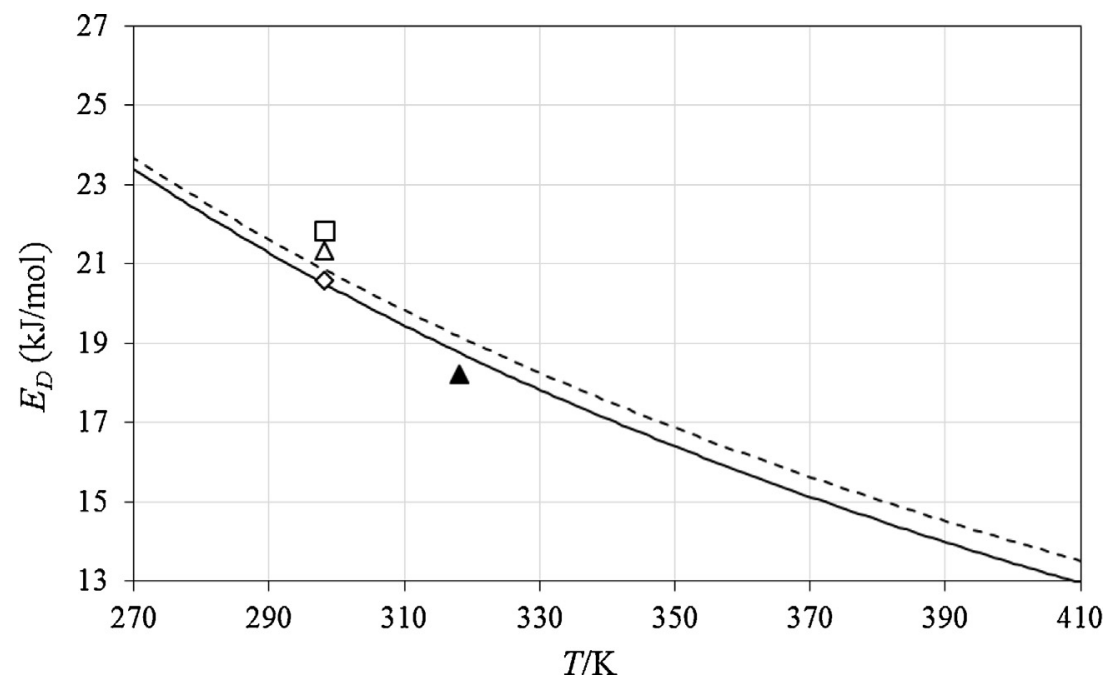

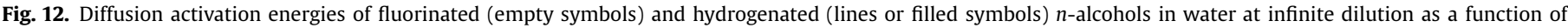

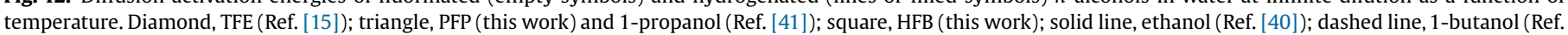
[40]).

\subsection{Simulation results}

Intra-diffusion coefficients of NFP in water and TFE and HFB in heavy water were obtained by computer simulation at $283.2 \mathrm{~K}$, $298.2 \mathrm{~K}$ and $313.2 \mathrm{~K}$. In the case of TFE in $\mathrm{D}_{2} \mathrm{O}$ two molar fractions were studied (0.001 and 0.005); for HFB, its water solubility limit precluded the simulation at the highest concentration. Since the solubility of NFP in water is very low, their solutions were modeled with a simulation box containing one solute molecule and 999 solvent molecules, which corresponds to infinite dilution.

The simulation results are presented in Table 6 and compared with the experimental data in Figs. 1-3 (in water) and Figs. 4 and 5 (in heavy water). The deviations of the simulated results for PFP, HFB and NFP in water are higher than those found for TFE in our previous work, increasing with temperature. The simulations underestimate the diffusion coefficients by $13-27 \%$ for PFP, $15-23 \%$ for HFB and $20-30 \%$ for NFP.
Intra-diffusion coefficients of TFE in heavy water are well predicted by the simulation, with deviations between 0 and $8 \%$ at $x_{1}=0.001$ and 7 and $13 \%$ at $x_{1}=0.005$. In this case, simulations slightly overestimate the property. For HFB in heavy water the deviations between simulated and experimental results are slightly lower than in normal water, between 5 and $21 \%$.

In order to check if these deviations were specific of the fluorinated alcohols, the intra-diffusion coefficients of 1-butanol in dilute aqueous solutions were also obtained by computer simulation. The results are presented in Table 7. For the hydrogenated alcohol, the diffusion coefficients were also underestimated, although with deviations slightly lower than for HFB.

As previously explained, simulation runs have also been performed using slightly different parameters for the fluorinated alcohols, following the model of Duffy [21,22] (obtained for TFE) and calculating the charge distribution by quantum mechanical methods. The simulations results using this model were practically 
Table 6

Intra-diffusion coefficients of NFP in water and TFE and HFB in heavy water at three different temperatures obtained by computer simulation $\left(D .10^{9}\right.$, in $\left.\mathrm{m}^{2} / \mathrm{s}\right)$. For NFP the composition shown is the proportion between solute and total molecules in simulation box and corresponds do infinite dilution.

\begin{tabular}{|c|c|c|c|}
\hline \multicolumn{4}{|c|}{$2,2,3,3,4,4,5,5,5$-Nonafluoropentan-1-ol in water } \\
\hline & \multicolumn{3}{|l|}{$T / \mathrm{K}$} \\
\hline$x$ (NFP) & 283.2 & 298.2 & 313.2 \\
\hline “0.001” & $0.41 \pm 0.03$ & $0.61 \pm 0.06$ & $0.86 \pm 0.09$ \\
\hline \multicolumn{4}{|c|}{ 2,2,2-Trifluoroethanol in $\mathrm{D}_{2} \mathrm{O}$} \\
\hline & \multicolumn{3}{|l|}{$T / \mathrm{K}$} \\
\hline$x$ (TFE) & 283.2 & 298.2 & 313.2 \\
\hline 0.001 & $0.62 \pm 0.04$ & $0.90 \pm 0.07$ & $1.36 \pm 0.08$ \\
\hline 0.005 & $0.62 \pm 0.03$ & $0.97 \pm 0.04$ & $1.36 \pm 0.05$ \\
\hline \multicolumn{4}{|c|}{$2,2,3,3,4,4,4$-Heptafluorobutan-1-ol in $\mathrm{D}_{2} \mathrm{O}$} \\
\hline & \multicolumn{3}{|l|}{$T / \mathrm{K}$} \\
\hline$x$ (HFB) & 283.2 & 298.2 & 313.2 \\
\hline 0.001 & $0.40 \pm 0.03$ & $0.61 \pm 0.04$ & $0.95 \pm 0.08$ \\
\hline
\end{tabular}

\section{Table 7}

Intra-diffusion coefficients of 1-butanol (1) in water (2) at three different temperatures obtained by computer simulation and comparison with experimental values of mutual diffusion coefficients. Simulated values at $x_{1}=0.001$. Experimental values at $x_{1}=0.00091(298 \mathrm{~K})$ and infinite dilution (remaining temperatures).

\begin{tabular}{llll}
\hline$T / \mathrm{K}$ & $\begin{array}{l}D_{1} \times 10^{9}\left(\mathrm{~m}^{2} / \mathrm{s}\right), \\
\text { simulation }\end{array}$ & $\begin{array}{l}D_{12} \times 10^{9}\left(\mathrm{~m}^{2} / \mathrm{s}\right), \\
\text { experiment }\end{array}$ & Deviation (\%) \\
\hline 283.2 & $0.53 \pm 0.04$ & $0.59[40]$ & -9.1 \\
298.2 & $0.78 \pm 0.04$ & $0.949[39]$ & -18.2 \\
313.2 & $1.1 \pm 0.1$ & $1.37[39]$ & -18.6 \\
\hline
\end{tabular}

identical to the presented ones, with differences well within the uncertainty of the method.

\section{Conclusions}

Intra-diffusion coefficients of three fluorinated alcohols in dilute aqueous solutions, 2,2,3,3,3-pentafluoropropan-1-ol (PFP), 2,2,3,3,4,4,4-heptafluorobutan-1-ol (HFB) and 2,2,3,3,4,4,5,5,5nonafluoropentan-1-ol (NFP), were measured by the PFG-NMR spin-echo technique as a function of temperature and composition. For comparison, intra-diffusion coefficients of 2,2,2-trifluoroethanol (TFE) and 2,2,3,3,4,4,4-heptafluorobutan-1-ol (HFB) in heavy water $\left(\mathrm{D}_{2} \mathrm{O}\right)$ were also measured.

Additionally, intra-diffusion coefficients of NFP in water and of TFE and HFB in heavy water were also obtained by molecular dynamics simulations and compared with the experimental results, together with those for the other alcohols obtained in previous work.

The results show that intra-diffusion coefficients of both fluorinated and hydrogenated alcohols are proportional to chain length and molecular weight. However, fluorinated alcohols display higher diffusion coefficients than hydrogenated alcohols with the same molecular weight. The higher mobility of fluorinated alcohols is probably due to the more hydrophobic nature of their fluoroalkyl chain, which results in a weaker interaction with water. Furthermore, the diffusion coefficients of both fluorinated and hydrogenated alcohols in water correlate with their partial molar volumes at infinite dilution.

The intra-diffusion coefficients of the $n$-fluoroalcohols in heavy water were found to be lower than those in water, which can be explained by the difference in viscosity between the two solvents.

The agreement between simulated and experimental results can be considered rather good, specially considering the intrinsic difficulties in predicting such a property, but it was found to be poorer than that obtained for TFE in our previous work. In all the cases, the simulations underestimate the intra-diffusion coefficients. We have found that these deviations are not specific for fluorinated alcohols as we found similar differences for 1-butanol.

Finally, diffusion activation energies were calculated from the temperature dependence of the diffusion coefficients and found to be very similar for all the systems except for TFE in water. For this alcohol the diffusion activation energy seems to be lower than for the other alcohols.

\section{Acknowledgements}

PM acknowledges funding from Fundação para a Ciência e Tecnologia (FCT) in the form of a post-doctoral grant (No. SFRH / BPD / 81748 / 2011). LFGM and JPPR also acknowledge funding from FCT through the grant PEst-OE/QUI/UI0619/2011. We also thank FCT for the funding of the NMR facility through RECI/QEQ-QIN/ $0189 / 2012$.

\section{References}

[1] R.C. Buck, J. Franklin, U. Berger, J.M. Conder, I.T. Cousins, P. de Voogt, A.A Jensen, K. Kannan, S.A. Mabury, S. van Leeuwen, Perfluoroalkyl and polyfluoroalkyl substances in the environment: terminology, classification, and origins, Integr. Environ. Assess. Manage. 7 (2011) 513-541.

[2] A. Drame', E.T. Givenchy, S.Y. Dieng, S. Amigoni, M. Oumar, A. Diouf, T. Darmanin, F. Guittard, Perfluoroalkyl and polyfluoroalkyl substances in the environment: terminology, classification and origins, Langmuir 29 (2013) $14815-14822$.

[3] J.G. Riess, Oxygen carriers (blood substitutes)-Raison d'Etre, chemistry, and some physiology, Chem. Rev. 101 (2001) 2797-2919.

[4] H.M. Courrier, T.F. Vandamme, M.P. Krafft, Reverse water-in-fluorocarbon emulsions and microemulsions obtained with a fluorinated surfactant, Colloids Surf. A: Physicochem. Eng. Aspects 244 (2004) 141-148.

[5] S. Rossi, C. Szíjjártó, F. Gerber, G. Waton, M.P. Krafft, Fluorous materials in microbubble engineering science and technology-design and development of new bubble preparation and sizing technologies, J. Fluor. Chem. 132 (2011) 1102-1109.

[6] J. Vymětal, J. Vondrášek, Parametrization of 2,2,2-trifluoroethanol based on the generalized amber force field provides realistic agreement between experimental and calculated properties of pure liquid as well as water-mixed solutions, J. Phys. Chem. B 118 (2014) 10390-10404.

[7] M. Sassi, Z. Atik, Excess molar volumes of binary mixtures of 2,2,2trifluoroethanol with water, or acetone, or 1,4-difluorobenzene, or 4fluorotoluene, or $\alpha, \alpha, \alpha$,trifluorotoluene or 1 -alcohols at a temperature of $298.15 \mathrm{~K}$ and pressure of $101 \mathrm{kPa}$, J. Chem. Thermodyn. 35 (2003) 1161-1169.

[8] Z.-T. Liu, J. Wu, L. Liu, L. Song, Z. Gao, W. Dong, J. Lu, Phase behavior of novel fluorinated surfactants in supercritical carbon dioxide, Green Chem. 8 (2006) 978-983.

[9] C.H. Rochester, J.R. Symonds, Densities of solutions of 4 fluoroalcohols in water, J. Fluor. Chem. 4 (1974) 141-148.

[10] M. Denda, H. Touhara, K. Nakanishi, Excess molar enthalpies for (water +a fluoroalkanol), J. Chem. Thermodyn. 19 (1987) 539-542.

[11] A. Cooney, K.W. Morcom, Thermodynamic behavior of mixtures containing fluoroalcohols. 1. (Water $+2,2,2$-trifluoroethanol), J. Chem. Thermodyn. 20 (1988) 735-741.

[12] A. Burakowski, J. Gliński, B. Czarnik-Matusewicz, P. Kwoka, A. Baranowski, K. Jerie, H. Pfeiffer, N. Chatziathanasiou, Peculiarity of aqueous solutions of 2,2,2trifluoroethanol, J. Phys. Chem. B 116 (2012) 705-710.

[13] K.R. Harris, P.J. Newitt, Z.J. Derlacki, Alcohol tracer diffusion, density, NMR and FTIR studies of aqueous ethanol and 2,2,2-trifluoroethanol solutions at 25 degrees C, J. Chem. Soc. Faraday Trans. 94 (14) (1998) 1963-1970.

[14] P. Duarte, M. Silva, D. Rodrigues, P. Morgado, L.F.G. Martins, Filipe, EJM, Liquid mixtures involving hydrogenated and fluorinated chains: ( $\mathrm{p}, \rho, \mathrm{T}, \mathrm{x})$ surface of (ethanol + 2,2,2-trifluoroethanol), experimental and simulation, J. Phys. Chem. B 117 (2013) 9709-9717.

[15] L.A.M. Pereira, L.F.G. Martins, J.R. Ascenso, P. Morgado, J.P.P. Ramalho, E.J.M Filipe, Diffusion coefficients of fluorinated surfactants in water: experimental results and prediction by computer simulation, J. Chem. Eng. Data 59 (2014) 3151-3159.

[16] D. Wu, A. Chen, C.S. Johnson Jr., An improved diffusion-ordered spectroscopy experiment incorporating bipolar-gradient pulses, J. Magn. Reson. A 115 (1995) 260-264.

[17] M. Holz, H. Weingärtner, Calibration in accurate spin-echo self-diffusion measurements using H-1 and less-common nuclei, J. Magn. Reson. 92 (1991) 115-125. 
[18] W.L. Jorgensen, D.S. Maxwell, J. Tirado-Rives, Development and testing of the OPLS all-atom force field on conformational energetics and properties of organic liquids, J. Am. Chem. Soc. 118 (45) (1996) 225-11236.

[19] J.L.F. Abascal, C. Vega, A general purpose model for the condensed phases of water: TIP4P/2005, J. Chem. Phys. 123 (2005) 234505-234512.

[20] W.L. Jorgensen, J. Chandrasekhar, J.D. Madura, R.W. Impey, M.L. Klein, Comparison of simple potential functions for simulating liquid water, J. Chem. Phys 792 (1983) 926-935.

[21] E.M. Duffy, Ph.D. Thesis, Yale University, 1994.

[22] R. Chitra, P.E. Smith, A comparison of the properties of 2,2,2-trifluoroethanol and 2,2,2-trifluoroethanol/water mixtures using different force fields, J. Chem. Phys. 115 (2001) 5521-5530.

[23] E.K. Watkins, W.L. Jorgensen, Perfluoroalkanes: conformational analysis and liquid-state properties from ab initio and monte carlo calculations, J. Phys. Chem. A 105 (2001) 4118-4125.

[24] A.A.H. Pádua, Torsion energy profiles and force fields derived from ab initio calculations for simulations of hydrocarbon-fluorocarbon diblocks and perfluoroalkylbromides, J. Phys. Chem. A 106 (2002) 10116-10123.

[25] U.C. Singh, P.A. Kollman, An approach to computing electrostatic charges for molecules, J. Comput. Chem. 5 (1984) 129-145.

[26] M.W. Schmidt, K.K. Baldridge, J.A. Boatz, S.T. Elbert, M.S. Gordon, J.H. Jensen, S. Koseki, N. Matsunga, K.A. Nguyen, S.J. Su, T.L. Windus, M. Dupuis, J.A. Montgomery, General atomic and molecular electronic-structure system, J. Comput. Chem. 14 (1993) 1347-1363.

[27] B. Hess, H. Bekker, H.J.C. Berendsen, J.G.E.M. Fraaije, LINCS: a linear constraint solver for molecular simulations, J. Comp. Chem. 18 (1997) 1463-1472.

[28] D. Van Der Spoel, E. Lindahl, B. Hess, G. Groenhof, A.E. Mark, H.J.C. Berendsen, GROMACS: fast, flexible and free, J. Comput. Chem. 26 (2005) 1701-1718.

[29] S. Pronk, S. Páll, R. Schulz, P. Larsson, P. Bjelkmar, R. Apostolov, M.R. Shirts, J.C. Smith, P.M. Kasson, D. van der Spoel, B. Hess, E. Lindahl, GROMACS 4.5: a HighThroughput and Highly Parallel Open Source Molecular Simulation Toolkit, Bioinformatics 29 (7) (2013) 845-854.

[30] H.J.C. Berendsen, Transport properties computed by linear response through weak coupling to a bath, in: M. Meyer, V. Pontikis (Eds.), Computer Simulations in Material Science, Kluwer, 1991, pp. 139-155.

[31] (a) S.A. Nosé, Molecular-dynamics method for simulations in the canonical ensemble, Mol. Phys. 52 (1984) 255-268; (b) W.G. Hoover, Canonical dynamics-equilibrium phase-space distributions, Phys. Rev. A 31 (1985) 1695-1697.

[32] (a) M. Parrinello, A. Rahman, Polymorphic transitions in single-crystals-a new molecular-dynamics method, J. Appl. Phys. 52 (1981) 7182-7190;

(b) S. Nosé, M.L. Klein, Constant pressure molecular-dynamics for molecularsystems, Mol. Phys. 50 (1983) 1055-1076.

[33] http://webbook.nist.gov/chemistry/.

[34] W.S. Price, H. Ide, Y. Arata, O. So1derman, Temperature dependence of the selfdiffusion of supercooled heavy water, J. Phys. Chem. B 104 (2000) 5874-5876.

[35] D.J. Wilbur, T. DeFries, J. Jonas, Self-diffusion in compressed liquid heavy water, J. Chem. Phys. 65 (5) (1976) 1783-1786.

[36] F.X. Prielmeier, E.W. Lang, R.J. Speedy, H.-D. Lüdemann, The pressure dependence of self-diffusion in supercooled light and heavy water, Ber. Bunsen-Ges. Phys. Chem. 92 (1998) 1111-1117.

[37] K. Yoshida, C. Wakai, N. Matubayasi, M. Nakahara, A new high-temperature multinuclear magnetic-resonance probe and the self-diffusion of light and heavy water in sub- and supercritical conditions, J. Chem. Phys. 123 (2005) 164506.

[38] unpublished results.

[39] L. Hao, D.G. Leaist, Binary mutual diffusion coefficients of aqueous alcohols. Methanol to 1-heptanol, J. Chem. Eng. Data 41 (1996) 210-213.

[40] T. Tominaga, S. Matsuomoto, Limiting Interdiffusion Coefficients of Some Hydroxylic Compounds in Water from 265-K to 433-K, J. Chem. Eng. Data 35 (1990) 45-47.

[41] K.C. Pratt, W.A. Wakeham, Mutual diffusion-coefficient for binary-mixtures of water and isomers of propanol, Proc. R. Soc. London A342 (1975) 401-419.

[42] unpublished results.

[43] T. Minamihonoki, H. Ogawa, H. Nomura, S. Murakami, Thermodynamic properties of binary mixtures of 2,2,2-trifluoroethanol with water or alkanols at T=298. $15 \mathrm{~K}$, Thermochim. Acta 459 (2007) 80-86.

[44] C. Jolicoeur, G. Lacroix, Thermodynamic properties of aqueous organic solutes in relation to their structure. Part III. Apparent molal volumes and heat capacities of low molecular weight alcohols and polyols at $25^{\circ} \mathrm{C}$. Can, J. Chem. 54 (1976) 624-631.

[45] C.R. Wilke, P. Chang, Correlation of diffusion coefficients in dilute solutions, AIChE J. 1 (1955) 264-270. 